\title{
A RELEVÂNCIA DO PIBID NA FORMAÇÃO E PRÁXIS DOCENTE DOS LICENCIANDOS EM MATEMÁTICA DA UNEB/CAMPUS $X$
}

\author{
Manoel SilvaDuarte ${ }^{1}$ \\ Joao Rodrigues Pinto 2
}

\section{Resumo}

O estudo é resultado de uma análise do Programa Institucional de Bolsa de Iniciação à Docência/PIBID e sua relevância na formação e práxis docente dos licenciandos em Matemática da Universidade do Estado da Bahia - UNEB/Campus X. Trata-se de uma pesquisa de abordagem qualitativa, que se sustenta na descrição analítica de dados observados em contexto natural e na interpretação de significados. O estudo foi realizado no cotidiano do Colégio Estadual Professor Rômulo Galvão - CEPROG, tendo como partícipes dois coordenadores, dois supervisores e dez alunos bolsistas do Programa. A coleta da dados se deu através de um questionário semiestruturado sobre o papel, a gestão e a importância do PIBID, com ênfase na iniciação à docência e na formação continuada. Os resultados apontam para uma avaliação positiva do PIBID, ressaltando-se a contribuição do programa para a formação e práxis docente e, sobretudo, a melhoria da qualidade da educação básica no Brasil, com vistas à promoção e valorização dos cursos de licenciatura.

Palavras-chave: Pibid, Formação, Práxis, Matemática.

\section{THE RELEVANCE OF PIBID IN UNEB / CAMPUS X MATHEMATICS LICENSE TRAINING AND PRACTICE}

Abstract: The study is the result of an analysis of the Institutional Program for Teaching Initiation Scholarship / PIBID and its relevance in the formation and praxis of teachers of Mathematics at the State University of Bahia - UNEB / Campus X. This qualitative approach is based on the analytical description of data observed in the natural context and on the interpretation of meanings. The study was carried out in the daily routine of the State College Professor Romulo Galvao - CEPROG, having as participants two coordinators, two supervisors and ten scholarship students of program. Data were collected through a semistructured questionnaire on the role, management and importance of PIBID, with emphasis on teaching initiation and continuing education. The results point to a positive evaluation of PIBID, highlighting the contribution of the program to teacher training and praxis and, above all, the improvement of the quality of basic education in Brazil, with a view to the promotion and enhancement of undergraduate courses.

Keywords: Pibid, Formation, Praxis, Mathematics.

\footnotetext{
${ }^{1}$ Mestrando em Educação (UNIGRENDAL). Especialista em Matemática (UNEB). Especialista em. (FVC-ES). Graduado em Matemática (UNEB). E-mail: mandumat@gmail.com.

${ }^{2}$ Professor Orientador. Doutor em Linguística e Língua Portuguesa (PUC-Minas). Mestre em Artes Cênicas (UNIRIO). Especialista em HISTÓRIA DO BRASIL (UFES); Graduado em LETRAS-Português (UFES); E-mail: jrprofessorr@hotmail.com.
} 


\section{CRIAR EDUCAÇÃO}

Revista do Programa de Pós-Graduação em Educação - UNESC

Criar Educação, Criciúma, v. 8, n², ago/dez 2019.- PPGE - UNESC - ISSN 2317-2452

\section{Introdução}

Este estudo apresenta a relevância de uma política de iniciação ao ensino de formação e práxis de professores de Matemática. No Brasil, as políticas públicas educacionais estão se ampliando há décadas com a finalidade de tornar o país uma nação emancipada no âmbito educacional. A intenção, portanto, encerra a discussão do papel da educação na construção da cidadania como ferramenta indispensável para a relação do sujeito com o mundo. Compete à educação, a garantia da aprendizagem de habilidades imprescindíveis para a vida em sociedade, promovendo ao educando, a capacidade para desenvolver a autonomia, bem como o espírito pesquisador e investigativo, oferecendo significado e sentido aos seus conhecimentos.

Esta proposta nasceu de inquietações pessoais durante 0 processo acadêmico e o momento final da formação profissional; desde o início do curso de Matemática, até o período da graduação e pós-graduação; e também, diante da experiência na área educacional, como professor, vice-diretor, e observações e vivências acerca do Pibid, analisando a formação dos professores de matemática e sua prática. Quando se finda o curso de graduação, ao se tornar profissional, uma etapa da vida está concluída, mas como se dá essa passagem do estado de aluno de Matemática, para o estado de profissional docente de Matemática? Que emoções, sentimentos e angústias se manifestam, ou mesmo habitam e interferem na busca de engajamento no mercado de trabalho? Quais dificuldades são encontradas neste ambiente em que a educação encontra-se em crise e a matemática é ainda um "bicho papão" para muitos estudantes? Muitos destes não aprenderam a ter um raciocínio lógico para a resolução de problemas matemáticos?

Depois de várias leituras sobre o tema, tornou-se perceptível que a origem de muitas dificuldades dos alunos, está na base, no ensino fundamental, que não foi bem realizado, assim o aluno não tem o domínio da matemática, e obviamente, apresentará deficiências na disciplina ao longo da sua vida. 
Para formar cidadãos capazes de compreender a importância de ministrar aulas de Matemática que geram uma aprendizagem significativa, é imprescindível organizar e planejar ações pedagógicas que envolvam o aluno, motivando-os a vivenciar diferentes formas de resolução de problemas matemáticos, aprimorando o raciocínio lógico.

A aprendizagem significativa é uma das metas do Programa Institucional de Bolsa de Iniciação à Docência/PIBID, como uma oportunidade de estimular a formação docente dos licenciandos em Matemática, a partir da realidade concreta da escola, convivendo com o cotidiano dos estudantes, professores e comunidade.

Nesse sentido, foi realizada uma pesquisa objetiva, portanto, analisar a relevância do PIBID na formação e práxis docente dos licenciandos em matemática da UNEB/Campus X, realizada no cotidiano da escola estadual CEPROG. O estudo discorre acerca do papel da Educação, das Políticas Públicas Educacionais, bem como seus efeitos na vida do cidadão e na realidade brasileira. Assim, contextualiza o Pibid, o conhecimento dos docentes na formação inicial e continuada em serviço e as atividades experienciadas no Programa.

Deve-se enfatizar que não basta à garantia do acesso e a permanência à escola, mas é preciso que a escola cumpra com a sua função social: tornar o homem humano, aparelhando-o para que ocupe os espaços sociais. Olhar a educação sob esse viés é buscar a melhoria da qualidade de ensino e profissionalização dos docentes, a humanização da escola, a valorização da comunidade escolar e, sovbretudo, a condição de trabalho dos docentes.

\section{Considerações do PIBID: abrangência e objetivos do programa}

O Programa Institucional de Bolsas de Iniciação ao Ensino (doravante Pibid), iniciado em meados dos anos 2000, abrange atualmente mais de 90.000 alunos distribuídos em mais de 300 projetos desenvolvidos em 05 regiões de Brasil (ARANTES, 2013). O PIBID é o cumprimento de uma exigência legal, estabelecida pela principal ordem educacional do país, a Lei de Diretrizes e Bases da Educação (LDB 9394/96), em seu artigo 62, §5은. 


\section{Criar Educação, Criciúma, v. 8, n², ago/dez 2019.- PPGE - UNESC - ISSN 2317-2452} pública por meio de um programa de bolsas institucionais para o ensino de alunos matriculados em cursos de graduação e pós-graduação em instituições de ensino superior (BRASIL,1996).

Os principais objetivos deste programa são: buscar a qualidade da formação de professores, a integração das instituições educacionais, escolas públicas de educação básica e programas de pós-graduação e expandir a produção e disseminação do conhecimento produzido a partir dos projetos. Por meio da aprovação da Constituição Federal em 1988, o financiamento da educação pública passou a ser prioridade, determinando em lei que $25 \%$ do orçamento fossem gastos em educação, pelos municípios e pelos Estados. Através disso, a educação pública passou a ser vista e discutida como um direito universal do ensino básico, garantindo o acesso de toda criança e também dos portadores de necessidades especiais à educação (GOMES, 2015).

Através de alguns resultados com projetos de Matemática ligados ao programa, podem ser listados aspectos importantes, tais como: a conexão entre teoria e prática, respeito pelas características regionais e locais na produção de conhecimento e na relação entre educação, pesquisa e extensão (NASCIMENTO, 2016). Além de melhorar a formação inicial de professores para a educação básica no Brasil, fomenta a formação continuada de professores que estão no ambiente de trabalho da prática profissional e que retornaram à universidade para refletir sua prática.

\section{O Pibid e a formação docente}

Para valorizar a profissão docente, incentivar a entrada da carreira docente na educação básica pública e atender a diferentes exigências legais quanto à formação de professores, para esse nível de ensino, o então ministro da Educação, Fernando Haddad, assinou a Portaria no 38 (BRASIL, 2007), deliberando normas para regulamentar e instituir os objetivos e outros critérios do programa.

Ao longo dos anos, o PIBID se expandiu consideravelmente em nível nacional. O programa, que atendeu cerca de três mil bolsistas no ano de 2007, atingiu quase 30 mil em 2011 e atualmente conta com mais de 90 mil (BRASIL, 2010). Segundo André (2012), embora não tenha sido feita uma avaliação mais 
Criar Educação, Criciúma, v. 8, n² 2, ago/dez 2019.- PPGE - UNESC - ISSN 2317-2452

abrangente sobre os impactos do PIBID, nem comparações entre profissionais graduados, as avaliações pontuais têm servido para demonstrar bons efeitos, tanto relacionados à motivação dos alunos para ingressar na profissão docente, quanto como a melhoria da formação continuada de profissionais que atuam como supervisores dos egressos.

Os estudos de Langer, Ribeiro e Schroeder (2013), relataram experiências de trabalho realizadas na Universidade Estadual do Oeste do Paraná (UNIOESTE) entre os anos 2010 e 2012, revelando situações, não apenas sobre práticas pedagógicas e interdisciplinares, mas, também a interação entre professores universitários, professores de escolas e bolsistas acadêmicos que fazem parte do PIBID.

A pesquisa realizada por Araújo, Andriola, Rodrigues e Coelho (2016) na Universidade Federal do Ceará (UFC), utilizando uma amostra de 84 graduados do PIBID durante o período de 2009 a 2014, destacou que o PIBID possibilitou considerável parte dos bolsistas se sentir mais seguro para atuar profissionalmente, para melhorar o desempenho acadêmico, superar certas dificuldades e desenvolver o gosto pelo ensino. Segundo os autores, tais indicações dão um impulso positivo e significativo às experiências decorrentes das atividades realizadas no âmbito do PIBID.

Percebe-se, a partir dos relatos, que a cooperação entre escola e universidade, propiciada pelo PIBID, vem contribuindo para o desenvolvimento de habilidades e para 0 aprofundamento teórico-metodológico das práticas pedagógicas, ampliando as ações no âmbito dos graus de bacharel e colaborando para uma nova perspectiva e concepção de formação inicial voltada para a prática profissional (CIANI et al., 2013). Além disso, houve uma mudança na concepção de ensino pelos professores universitários, fazendo-os entender que o exercício do ensino exige muito mais do que o domínio do conteúdo (SILVEIRA, 2013).

Esses aspectos relacionados aos benefícios do PIBID para a formação de estudantes de graduação também podem ser encontrados na pesquisa realizada por Darroz e Wannmacher (2015) que objetivou identificar o foco da formação de professores de graduação em física, participantes dos subprojetos do programa no estado brasileiro de ensino. Rio Grande do Sul. Os autores referenciados 
Criar Educação, Criciúma, v. 8, n²2, ago/dez 2019.- PPGE - UNESC - ISSN 2317-2452

verificaram, com base nos relatos de 32 egressos, que os acadêmicos adquirem diversas habilidades, se sentem mais seguros, são levados a pesquisar e estudar mais para resolver problemas detectados em sala de aula durante as atividades do programa, assim como desenvolver competências relacionadas com o exercício do ensino.

O PIBID foi bem-sucedido em auxiliar a educação continuada de professores das escolas participantes dos subprojetos. Fetzner e Souza (2012), em estudo realizado na Universidade Federal do Estado do Rio de Janeiro (UNIRIO), sobre a interculturalidade, os desafios contemporâneos e a perspectiva conservadora e emancipatória do conhecimento escolar, constataram que nas escolas, onde se desenvolve o PIBID, foram intensificadas as perspectivas interculturais, normalmente negligenciadas pelas escolas.

No entanto, embora o PIBID tenha apresentado bons resultados, principalmente em relação à qualificação da formação de professores, combatendo a baixa profissionalização e atratividade da carreira docente, constituindo-se como grande aliada da escola pública, os problemas existentes no ensino superior do país dificultam o recrutamento de professores mais qualificados (ARANTES, 2013).

Percebe-se que o sucesso do PIBID, depende de um conjunto de fatores que, juntos, influenciam futuros professores, especialmente no contexto escolar. De acordo com Langer, Ribeiro e Schroeder (2013), vale ressaltar, como relevante, que a forma como os bolsistas do PIBID se relacionam com a escola pública, com os supervisores, com a equipe pedagógica e até com outros professores parece fazer muita diferença no processo de formação, podendo influenciar positivamente ou negativamente na escolha da profissão e ambiente de trabalho.

\section{O PIBID e a prática docente dos licenciandos em Matemática da UNEB/Campus} $X$, na instituição de ensino CEPROG

Um dos principais desafios que as universidades enfrentam, nos cursos de licenciatura, tem sido o de auxiliar o futuro professor a entender a docência enquanto profissão, oportunizando uma visão mais ampla sobre a complexidade, especificidade e as possibilidades da atuação docente no meio social. 
Esse desafio tem sido compartilhado por vários formadores, sendo que, nos cursos de licenciatura, as disciplinas de prática pedagógica constituem-se como lócus privilegiado para superá-lo, principalmente por representarem um espaço onde tensões significativas são evidenciadas (VEIGA, 2012). O PIBID, portanto é uma política educacional de apoio aos professores iniciantes no Brasil como parte de uma política de educação continuada. Sendo esta iniciativas recente, mas muito promissora na tentativa de minimizar os problemas enfrentado pelos professores iniciantes (ANDRÉ, 2012).

Quanto ao aspecto da formação docente, a Lei de Diretrizes e Bases da Educação Nacional (LDB) afirma, em seu Art. 61, a necessidade de "formação de profissionais da educação de modo a atender aos objetivos dos diferentes níveis e modalidades de ensino e as características de cada fase do desenvolvimento do educando" (BRASIL, 1996).

É preciso que se diga da necessidade de uma formação específica que possibilite uma maior compreensão ao futuro professor, de forma a superar a visão restrita e utilitarista, destacando a relevância do Pibid para a educação. Neste sentido, Machado (2015) afirma que grande parte dos cursos de formação de professores prepara os futuros docentes para atuar com o aluno ideal - por que não dizer irreal. São aprendidos os conteúdos das áreas específicas, no caso aqui, a área de Matemática, conhecem-se determinadas ferramentas pedagógicas e metodológicas, entretanto está-se distante de discorrer a realidade concreta da unidade de ensino na qual irá atuar, ao assumir um contrato temporário ou, ainda, ao ser aprovado em um concurso para cargos efetivos nas redes públicas de ensino.

Desse modo, a formação através do Pibid, aparece como uma ferramenta imprescindível no processo de formação do futuro professor de Matemática, como afirma Gomes (2015), conferindo-Ihe um período de desenvolvimento de atividade prática instrumental, vivência de desafios da realidade nos espaços escolares, interação com os mais diversos perfis sociais e comportamentais dos alunos, o que, naturalmente, faz também desse momento, uma ferramenta de pesquisa e desenvolvimento de novas práticas educativas.

Nesse aspecto, percebe-se que o PIBID tem sido um fator determinante na formação dos licenciandos. De acordo com as literaturas estudadas, verifica-se que 
a participação dos alunos no PIBID colabora para a valorização dos docentes e também, para o avanço da qualidade da formação inicial de professores integrados à Educação Básica.

\section{Caminho metodológico}

A raiz metodológica em questão é de natureza qualitativa, se sustenta na descrição analítica de dados observados em contexto natural e na interpretação de significados. É um estudo teórico-prático, fundamentado também na perspectiva de Martins (2001, p. 58), quando afirma:

No que se refere à pesquisa qualitativa, pode-se dizer que os dados são coletados através da descrição feita pelos sujeitos [...] uma questão metodológica importante é a que se refere ao fato de que não se pode insistir em procedimentos sistemáticos que possam ser previstos, em passos ou sucessões como uma escada em direção à generalização.

Telles (2002) afirma que nos dias atuais, essa metodologia de pesquisa qualitativa tem tido mais destaque quando o objeto de pesquisa é a educação. Dada a natureza da pesquisa qualitativa e a necessidade de obter maiores informações para o enriquecimento do estudo, será entregue, a princípio, um questionário semiestruturado aos alunos em iniciação à docência - ID de Matemática, partícipes do PIBID na Escola CEPROG, para melhor interpretação das informações e construção do estudo. A posteriori, um questionário semelhante será entregue ao supervisor e coordenadores.

Os critérios de inclusão empregados para que ocorresse a busca foram de livros, periódicos e artigos científicos, todos publicados entre os anos de 1992 a 2011. Foram utilizados como descritores: Pibid, Iniciação à Docência, Formação continuada, Aprendizagem. O Pibid é um dos elementos empíricos e analíticos dessa pesquisa. Entrevistas semiestruturadas com questionários, trabalho de campo e pesquisas são alguns dos instrumentos dessa coleta de dados.

\section{Análise dos dados}

$\mathrm{Na}$ análise relacionada à opinião dos coordenadores e supervisores e também, dos professores, $100 \%$ dos colaboradores da pesquisa mencionaram que o 


\section{CRIAR EDUCAÇÃO}

Revista do Programa de Pós-Graduação em Educação - UNESC

Criar Educação, Criciúma, v. 8, n² 2, ago/dez 2019.- PPGE - UNESC - ISSN 2317-2452

PIBID é um fator que determina a melhoria da qualidade da educação básica no Brasil e também que o PIBID/Matemática visa à promoção e valorização dos cursos de licenciatura. Entretanto, $72 \%$ deles afirmaram que a participação no PIBID/Matemática aumenta o desejo de continuação no curso de Licenciatura, 17\% discordam dessa afirmação e $11 \%$ não apresentaram opinião conforme registra o Gráfico 1.

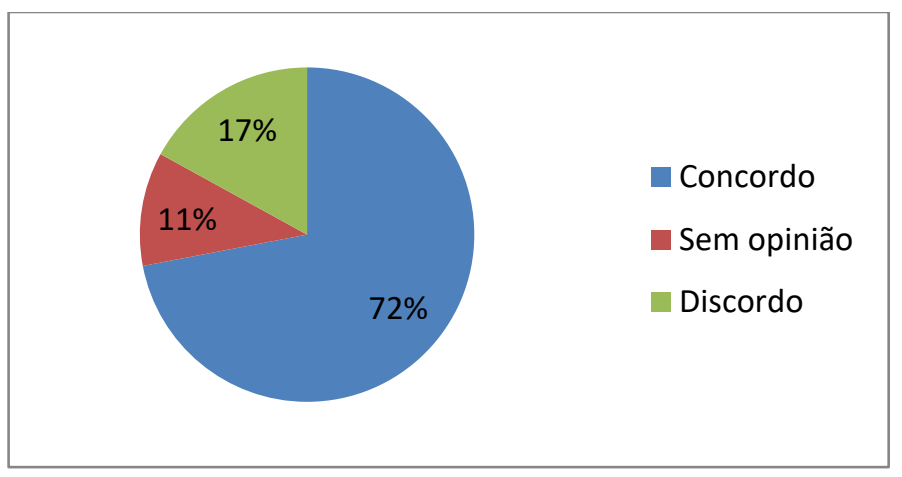

Gráfico 01: Participação no PIBID/Matemática.

Fonte: Dados da Pesquisa (2018).

$85 \%$ afirmaram que existiu uma relação de colaboração entre a universidade e a escola de Educação Básica, 5\% discordaram e 10\% não emitiram opinião.

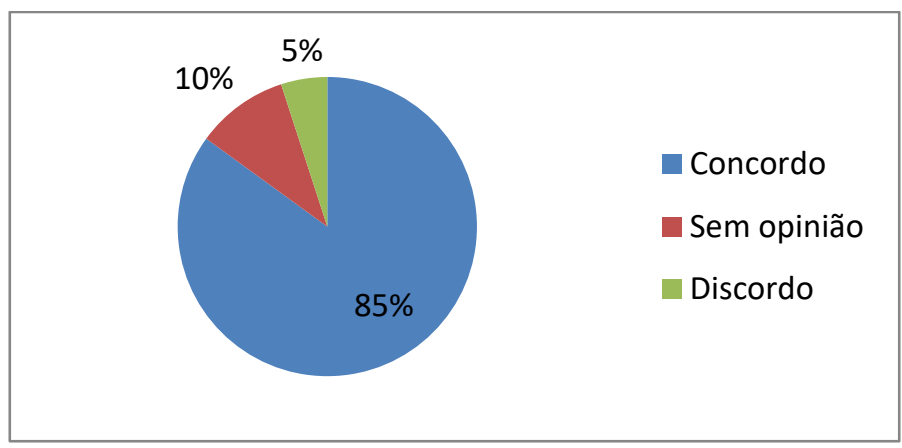

Gráfico 02: Colaboração entre a universidade e a Escola. Fonte: Dados da Pesquisa (2018).

89\% dos partícipes da pesquisa consideraram que a qualidade do ensino na escola em que trabalham é melhorada pelas ações do PIBID/Matemática. 5\% discordam e $6 \%$ não têm opinião. 


\section{CRIAR EDUCAÇÃO}

Revista do Programa de Pós-Graduação em Educação - UNESC

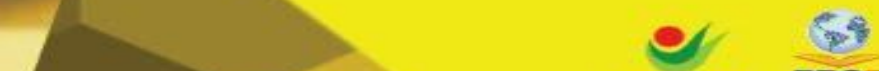 \\ unesc}

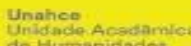

Criar Educação, Criciúma, v. 8, n², ago/dez 2019.- PPGE - UNESC - ISSN 2317-2452

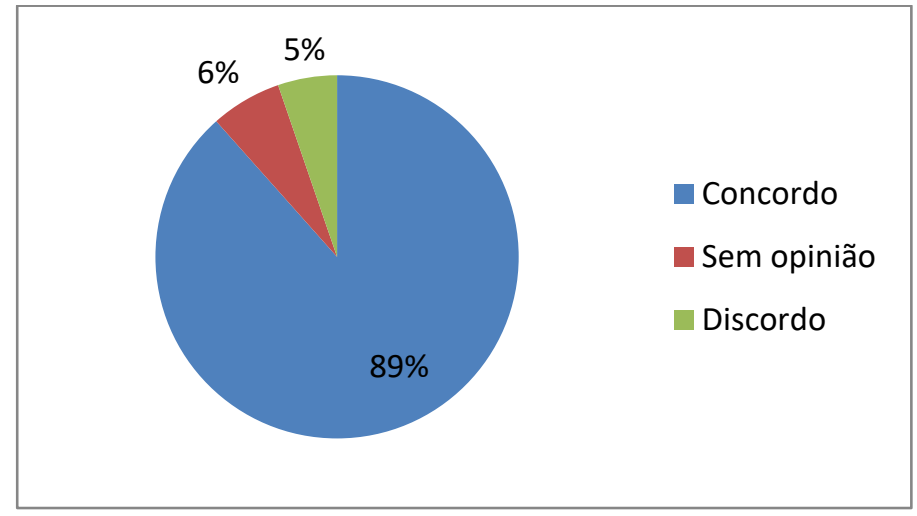

Gráfico 03: Qualidade do ensino na escola.

Fonte: Dados da Pesquisa (2018).

Quando questionados se, na atualidade, o PIBID/Matemática aprimorou o entendimento acerca do processo de ensino-aprendizagem, 95\% citaram que concordam com esta assertiva.

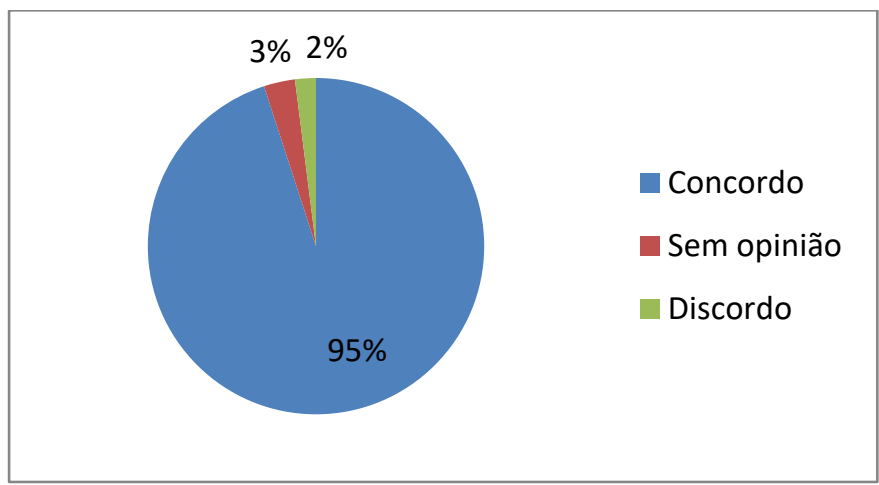

Gráfico 04: O PIBID/Matemática aprimora o entendimento Fonte: Dados da Pesquisa (2018).

Em relação à questão, no PIBID/Matemática, se o trabalho em equipe efetivado na unidade escolar, amplia os conhecimentos sobre a educação, $96 \%$ afirmaram que concordam com a afirmação, $1 \%$ discorda e 3\% não têm opinião.

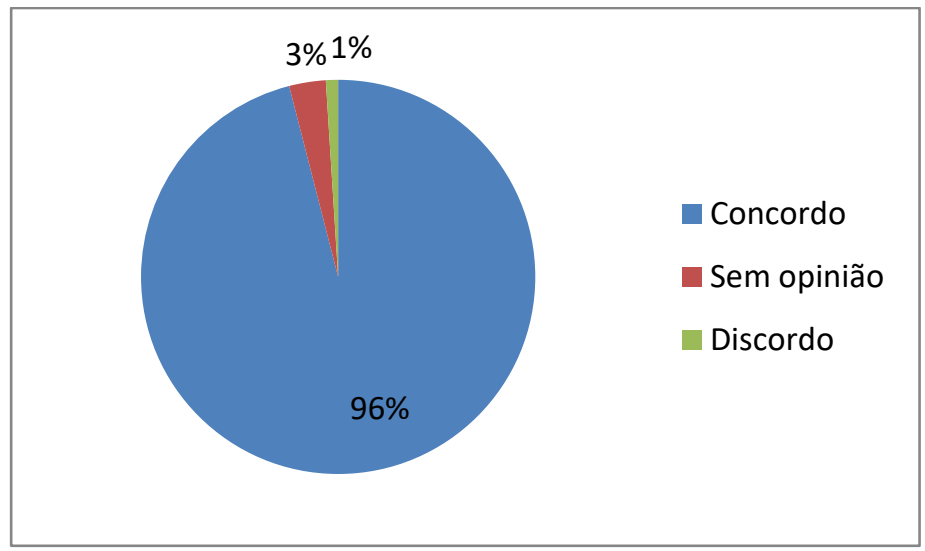




\section{CRIAR EDUCAÇÃ̃o}

Revista do Programa de Pós-Graduação em Educação - UNESC

Criar Educação, Criciúma, v. 8, n² 2, ago/dez 2019.- PPGE - UNESC - ISSN 2317-2452

Gráfico 05: O trabalho em equipe na unidade escolar

Fonte: Dados da Pesquisa (2018).

Em se tratando do questionamento sobre a participação efetiva no PIBID/Matemática ter modificado a visão sobre a profissão de professor de matemática, $100 \%$ dos entrevistados no questionário para supervisores e coordenadores e também, professores integrantes da iniciação à Docência no CEPROG, afirmaram que concordam com esta afirmação.

No entanto, apenas $45 \%$ disseram que o PIBID influenciou na definição de atuar como professor de matemática na Educação Básica ao concluir a licenciatura. $25 \%$ discordam e $30 \%$ não têm opinião.

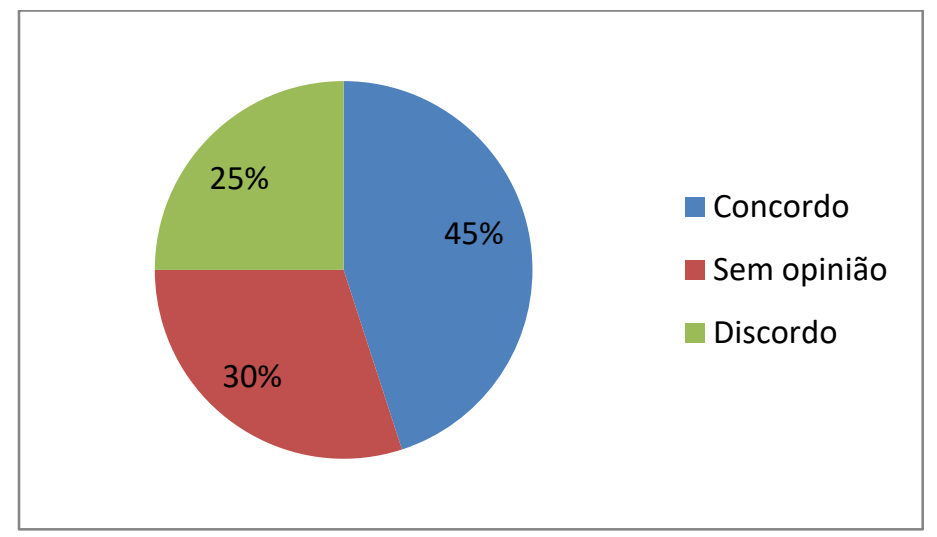

Gráfico 06: O trabalho em equipe amplia os conhecimentos Fonte: Dados da Pesquisa (2018).

$100 \%$ dos professores formadores possuem a preocupação em demonstrar que a relação entre teoria e práxis deve ser indissociável no processo de formação, inclusive por terem feito parte do PIBID/Matemática e compreendido a realidade escolar e a atuação profissional dos docentes de matemática, que os auxiliaram a pensar que esta é realmente a profissão a ser seguida.

$100 \%$ concordaram que usar distintos ambientes virtuais para disponibilização de materiais e promoção de discussões entre os discentes visando potencializar o ensino de Matemática é relevante para o futuro professor de matemática. Todos afirmaram que participaram de uma Comunidade de Prática (PIBID/Matemática) onde há uma dinâmica de troca de informações e contribuições, por iniciativa ou interesse. 


\section{CRIAR EDUCAÇÃOO}

Revista do Programa de Pós-Graduação em Educação - UNESC

\section{$\rightarrow \quad 0$ \\ unesc \\ PPG

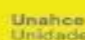

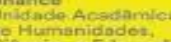 \\ ediunese}

Criar Educação, Criciúma, v. 8, n², ago/dez 2019.- PPGE - UNESC - ISSN 2317-2452

Com relação às trocas de informações entre os membros (processo de ensino/aprendizagem) da comunidade de prática PIBID/Matemática, 90\% citam que concordam que há essa troca, $8 \%$ discordam e $2 \%$ não possuem opinião (Gráfico 7).

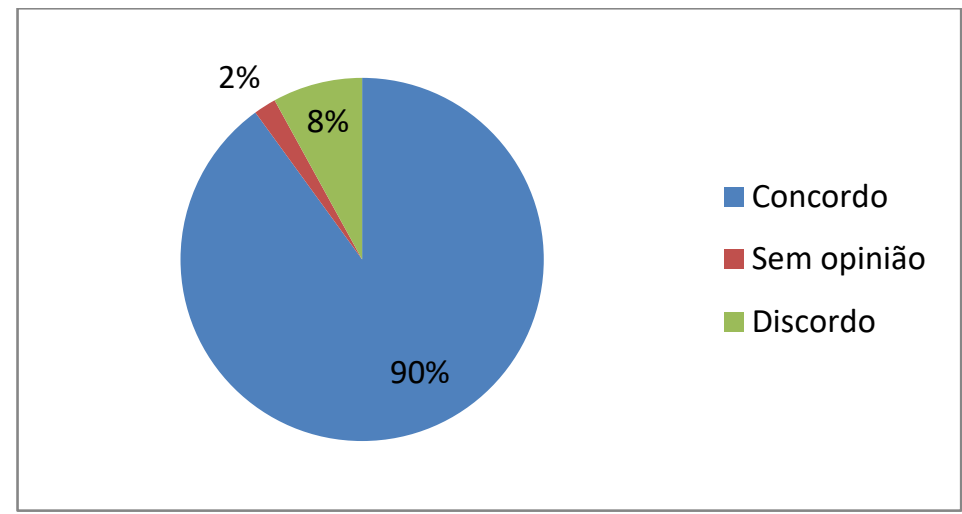

Gráfico 07: Informações entre os membros da comunidade Fonte: Dados da Pesquisa (2018).

\section{Resultados e Discussão}

Após a análise dos dados, verificou-se que a maioria dos entrevistados concorda com a relevância e continuidade do Pibid/Matemática para a iniciação, formação e prática docente. O envolvimento dos professores de Matemática na pesquisa foi de fundamental importância na perspectiva de demonstrar a importância do Pibid para propiciar um efetivo processo de ensino-aprendizagem mediado pela política de iniciação ao ensino de formação e práxis de professores de Matemática, contribuindo também para a formação continuada deste profissional.

\section{Considerações Finais}

O Pibid é o cumprimento de uma exigência legal estabelecida pela LDB 9394/96, em busca da qualidade da formação de professores, a integração das instituições educacionais, escolas públicas de educação básica e programas de pósgraduação e expandir a produção e disseminação do conhecimento produzido a partir dos projetos. Compete à educação a garantia da aprendizagem de habilidades imprescindíveis para a vida em sociedade, promovendo ao educando, a capacidade para desenvolver a sua autonomia, bem como o espírito pesquisador e investigativo, oferecendo significado e sentido aos seus conhecimentos. 
Compreende-se que é grande a relevância do Pibid na formação e práxis docente dos licenciandos em matemática da UNEB/Campus $X$, realizada no cotidiano da escola estadual CEPROG, uma vez que é necessária a formação de cidadãos aptos à compreensão da importância de ministrar aulas de Matemática com qualidade gerando um ensino proveitoso, eficaz, uma educação de qualidade.

Um dos desafios a serem superados para um ensino da matemática de qualidade é o desafio enfrentado pelas universidades em qualquer curso de licenciatura, o de colaborar para que o futuro professor compreenda a docência enquanto profissão, trazendo-Ihe uma visão ampliada acerca da complexidade, peculiaridades e as possibilidades da atuação docente no meio social. Outro desafio refere-se à continuidade e permanência do Pibid nas escolas de Ensino Fundamental e Médio. Assim, faz-se necessário que haja a formação continuada de professores e práxis docente e o desenvolvimento de estratégias para a continuação do Pibid, uma vez que na atualidade, o Pibid de matemática não está mais acontecendo no CEPROG.

\section{Referências}

ANDRÉ, M. Políticas e programas de apoio aos professores iniciantes no Brasil. Cadernos de Pesquisa, São Paulo, v. 42, n. 145, p.112-129, 2012.

ARANTES, M. A. A prática docente e o ensino de sociologia, p. 27-46. In: LANGER, Arleni Elise Sella; RIBEIRO, Dulcyene Maria; SCHROEDER, Tânia Maria Rechia (org.). PIBID: incentivo à formação de professores. Porto Alegre: Evangraf/UNIOESTE, 2013.

ARAÚJO, A. C. Avaliação do Programa Institucional de Bolsa de Iniciação à Docência da Universidade Federal do Ceará na perspectiva dos egressos. Dissertação de Mestrado apresentada ao Mestrado Profissional em Políticas Públicas e Gestão da Educação Superior (POLEDUC). Fortaleza: Universidade Federal do Ceará (UFC), 2015, 90 p.

ARAÚJO, A. C.; ANDRIOLA, W. B.; RODRIGUES, M. do S. de S.; COELHO, A. de A. Avaliação do Programa Institucional de Bolsa de Iniciação à Docência (PIBID): estudo de caso na Universidade Federal do Ceará (UFC). Revista Foro Educacional, Chile, n. 27, p. 33-56, 2016.

BRASIL. Constituição da República Federativa do Brasil. 35. ed. Brasília: Biblioteca Digital da Câmara de Deputados, 2012. 
BRASIL. Decreto no 7.219, de 24 de junho de 2010. Dispõe sobre o Programa Institucional de Bolsa de Iniciação à Docência - PIBID e dá outras providências. Brasília, DF, 2010. Disponível em: <http://goo.gl/U3SqzP>. Acesso em: 22 dez. 2018.

BRASIL. Lei no 9.394, de 20 de dezembro de 1996. Estabelece as diretrizes e bases da educação nacional. Brasília, DF, 1996.

BRASIL. Portaria no 38, de 12 de dezembro de 2007. Ministério da Educação. Dispõe sobre o Programa de Bolsa Institucional de Iniciação à Docência - PIBID. Brasília, DF, 2007. Disponível em: <http://goo.gl/PxTFMf>. Acesso em: 27 dez. 2018.

CIANI, A. B.; LANGER, A. E. S.; RIBEIRO, D. M.; ANTUNES, F. C. A.; BASSOI, T. S. A experiência do PIBID na licenciatura de matemática da Unioeste - campus de Cascavel, p. 61-75. In: LANGER, A. E. S.; RIBEIRO, D. M.; SCHROEDER, T. M. R. (org.). PIBID: incentivo à formação de professores. Porto Alegre: Evangraf/UNIOESTE, 2013.

DARROZ, L M.; WANNMACHER, C. M. D. Aprendizagem docente no âmbito do PIBID/física: a visão dos bolsistas de iniciação à docência. Revista Ensaio: Pesquisa em Educação em Ciências, v. 17, p. 727-748, 2015. Disponível em:<http://www.scielo.br/scielo.php?pid=S1983-

21172015000300727\&script=sci_abstract\&tlng=pt>. Acesso em: 24 dez. 2018.

FETZNER, A. R.; SOUZA, M. E. V. Concepções de conhecimento escolar: potencialidades do Programa Institucional de Bolsa de Iniciação à Docência. Educação e Pesquisa, São Paulo, v. 38, n. 3, p. 683-694, 2012.

GOMES, Lisiane Santos. A importância do Pibid na formação e prática docente dos licenciandos em matemática da Uesb campus de Vitória da Conquista. Monografia de Graduação em Matemática da Universidade Estadual do Sudoeste da Bahia. Vitória da Conquista: Universidade Estadual do Sudoeste da Bahia (UESB), 2015, 41 p.

LANGER, A. E. S.; RIBEIRO, D. M.; SCHROEDER, T. M. R.(org.). PIBID: incentivo à formação de professores. Porto Alegre: Evangraf/UNIOESTE, 2013.

MARTINS, Joel. Metodologia da pesquisa educacional. São Paulo: Cortez, 2001.

NASCIMENTO, Maria Anezilany Gomes do. Impactos do Programa PIBID na Formação de Professores e na Educação Geográfica, no Brasil. 2016. Disponível em: <https://www.researchgate.net/publication/307608944_Impacts_of_the_Program_PI BID_in_Teacher_Training_and_Geographical_Education_in_Brazil>. Acesso em: 12 nov. 2018.

SILVEIRA, J. A.P. da. Ensaio: confissões de um observador sem método das impressões em segunda mão das escolas de ensino médio do Paraná, p. 97-107. In: 
LANGER, A. E. S.; RIBEIRO, D. M.; SCHROEDER, T. M. R. (org.). PIBID: incentivo à formação de professores. Porto Alegre: Evangraf/UNIOESTE, 2013.

TELLES, J. A. "É pesquisa, é? Ah, não quero, não, bem!" Sobre pesquisa acadêmica e sua relação com a prática do professor. Linguagem \& Ensino, Vol. 5, N. 2, 2002 (91-116).

VEIGA, I. P. A. Docência como Atividade Profissional. p. 13-22. In: VEIGA, I. P. A; D"ÁVILA, C. (Orgs.). Profissão docente: novos sentidos, novas perspectivas. 2. ed. Campinas: Papirus, 2012, 176p.

Recebido 30 de maio de 2019

Aprovado 25 de agosto de 2019. 